\title{
Efficiency of Selective Oil Degrading Active Bacteria in Bio augmentation of Oil Sludge at Different Concentration Levels: A Laboratory Scale
}

\author{
Nur Zaida, Z., Piakong, M.T \\ Faculty of Science \& Natural Resources, Universiti Malaysia Sabah, \\ UMS Road, 88400 Kota Kinabalu,Sabah Malaysia.
}

\begin{abstract}
A laboratory scale experiment was conducted to compare the ability of selective locally isolated oil degrading bacteria to enhance oil sludge contaminated soil at different concentration levels. Five different active strains (C.tropicalis-RETL-Crl, C. violaceum-MAB-Crl, P. aeruginosa-BAS-Crl, S. paucimobilis-ReTOSCrland S. maltophilia-RAS-Crl)used in this study were obtained from Environmental Microbiology Laboratory, Faculty of Science \& Natural Resources, Universiti Malaysia Sabah. Their ability to degrade hydrocarbons contaminated soil was investigated in a bioreactor made up of acrylics material assisted by aerated static pile (ASP) model Resun LP100. There are 2 sets of experiments containing $10 \mathrm{~kg}$ of soil with addition of $5 \%$ and $10 \%$ oil sludge were prepared as Treatment A (contaminated soil $+C$. tropicalis-RETL-Cr1), Treatment $B$ (contaminated soil $+C$. violaceum-MAB-Crl), Treatment $C$ (contaminated soil $+P$. aeruginosa-BAS-Crl), Treatment $D$ (contaminated soil $+S$. paucimobilis-RETOS-Crl), Treatment E (contaminated soil $+S$. maltophilia-RAS-Crl) and Treatment $F$ (contaminated soil without bacterial inoculation (Natural attenuation)). The experiments were incubated for 60 days periods and the TPH reduction was observed along with physiochemical parameters such as $\mathrm{pH}$, moisture content and microbial population (CFUs). The results showed that removal efficiency of TPH at 5\% concentration oil sludge was recorded as; Treatment $C(80 \%)>$ Treatment $D(74 \%)>$ Treatment $E(67 \%)>$ Treatment $A(65 \%)>$ Treatment $B(64 \%)>$ Treatment $F(22 \%)$. For treatment at $10 \%$ concentration oil sludge, the removal of TPH was as followed; Treatment $C$ (81.6\%)>Treatment B $(80.7 \%)>$ Treatment $D(80.4 \%)>$ Treatment $A(80 \%)>$ Treatment $E(79.2 \%)>$ Treatment $F(54 \%)$. It was observed that treatment with P. aeruoginosa-BAS-Crl was performed best in biodegradation of oil sludge by showing dramatics reduction in TPH with residual $10 \mathrm{~g} / \mathrm{kg}$ (at 5\% oil sludge) and $18.4 \mathrm{~g} / \mathrm{kg}$ (at $10 \%$ oil sludge) respectively. This finding also demonstrated that the higher contaminants levels in soil, the higher removal TPH can be achieved after 60 days of treatments. The variation on physiochemical parameters in the soil were also discussed in this paper.
\end{abstract}

Keywords: Bioremediation, Oil sludge, Oil degrading bacteria, Different concentration levels, Aerated static pile

\section{Introduction}

Petroleum is one of the most important substances consumed by people around the world. A high demand of this product has produce considerable amount of oily sludge generated from refining process, petrochemical process, storage and transportation. This sludge usually contains of hydrocarbons, sediments, water and heavy oil. The chemical composition of oil sludge can be categorized as four fractions of alkanes, aromatics, asphaltenes and resin (Diallo et al., 2000). This component has high content of hydrocarbons in the range of 140 carbon atoms [21]. Oil sludge has been classified by the United States Environment Protection Agency (USEPA) as a hazardous organic complex [21]. The release of these components into the environment due to anthropogenic activities or accidental spills can pose a serious threat to water and soil pollution [7] These include the physical and chemical alteration of natural habitats, lethal and sub-lethal toxic effects on aquatic, terrestrial ecosystem and human health. There are various technologies introduced for removal of hydrocarbon in contaminated site. This method includes incineration, thermal desorption, chemical oxidation, immobilization and solvent extraction [9]. However, these treatments are very expensive, energy intensive, and not suitable with respect to environmental impacts. Biological degradation also known as bioremediation appears to be the main process responsible for the removal of hydrocarbons in soil [23]. The addition of selective oil degrading bacteria 
to augment the biodegradation capacity can accelerate the growth of the population naturally microorganism that preferentially feed on the contaminants at the site. This technology also believed to be non-invasive and relatively cost effective [8]. Besides of cost effectiveness, this method also is permanently solution which may lead to complete mineralization of the pollutant. In this paper, we highlight the potential of selective oil degrading bacteria in bioaugmentation of oil sludge contaminated soil at different concentration levels enhanced by aerated static pile (ASP).

\section{Materials and Methods}

\subsection{Bioreactor Design}

A bioreactor made up of acrylic material with dimension of $60 \mathrm{~cm}$ x $40 \mathrm{~cm}$ x $20 \mathrm{~cm}$ with 3 tubing for aeration at the side of the reactor connected to air pump (Model RESUN LP100 Low Noise Air Pump) [22] were prepared. (Figure 1). The reactor were divided into 3 parts where the base is filled with gravel-sized $(1-1.5 \mathrm{~cm})$ followed by sand $(3 \mathrm{~cm})$ and soil $(3 \mathrm{~cm})$ on the surface. The soils used in the study were mixed thoroughly before being put in the treatment plot.

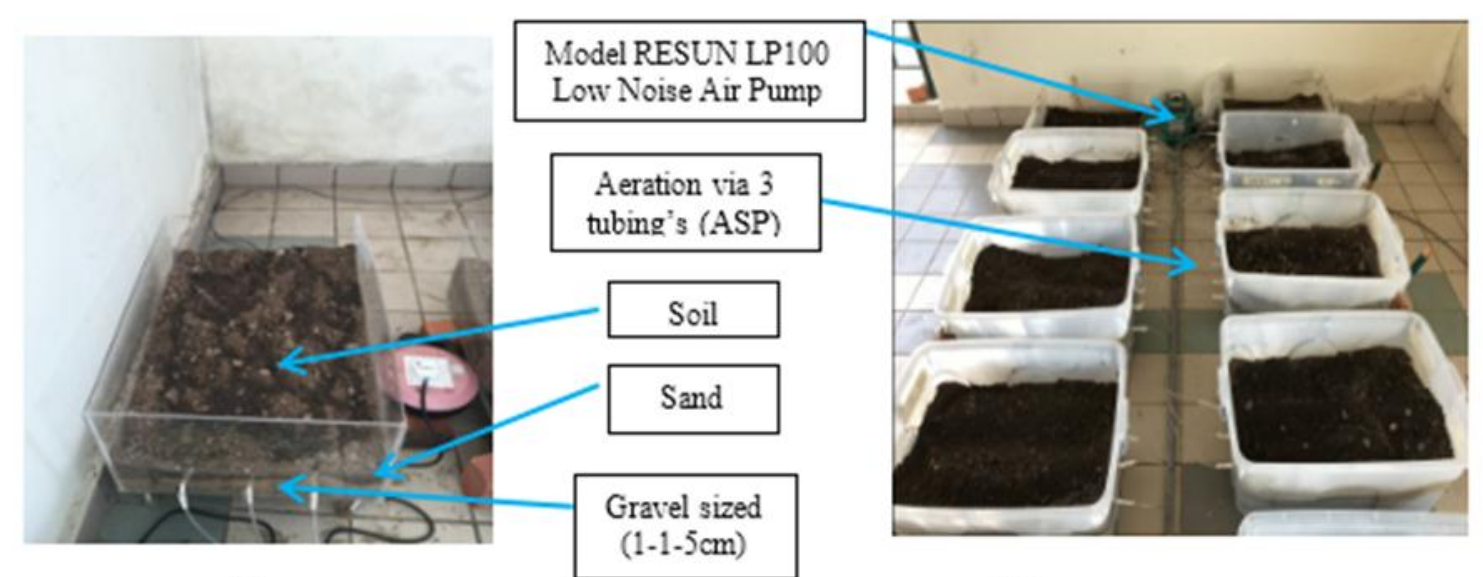

(a)

(b)

Fig.1: Bioreactor set up for ASP-bioaugmentation of oil sludge (a) side view and (b) top view.

\subsection{Bacterial Strain}

Bacterial strains used in this study were obtained from Environmental Microbiology Laboratory, Faculty of Science \& Natural Resources at Universiti Malaysia Sabah. These collections of hydrocarbon degrading bacteria (Figure 2) have been proven to degrade oil and phenol based on the previous research done by [14][12].

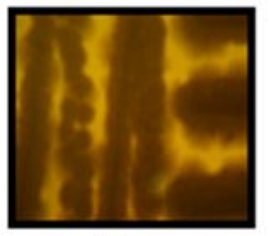

(a)

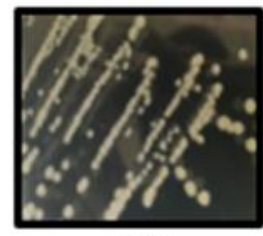

(b)

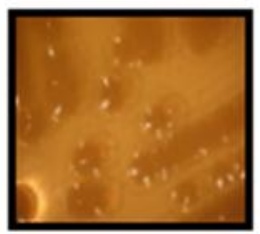

$m(c)$

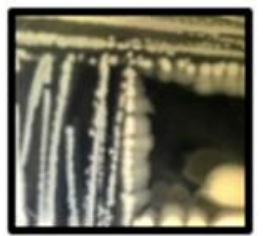

(d)

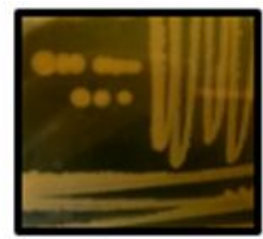

(e)

Fig. 2 Selected hydrocarbon degrading bacteria used (a) Sphingomonas paucimobilis-ReTOS-Cr1, (b) Candida tropicalisRETL-Cr1, (c)Pseudomonas aeruginosa-BAS-Cr1(d) Chromobacterium violaceum-MAB-Cr1 and (e) Stenotrophomonas maltophilia-RAS-Cr1 obtained from Environmental Microbiology Laboratory, FSSA, UMS.

\subsection{Culture Medium}

Ramsay broth was used in this study as according to [15]. Approximately $2.0 \mathrm{gL}^{-1}$ of $\mathrm{NH}_{4} \mathrm{NO}_{3}, 0.5 \mathrm{gL}^{-1}$ of $\mathrm{KH}_{2} \mathrm{PO}_{4}, 1.0 \mathrm{gL}^{-1}$ of $\mathrm{KHPO}_{4}, 0.1 \mathrm{gL}^{-1}$ of $\mathrm{KCl}, 0.01 \mathrm{gL}^{-1}$ of $\mathrm{CaCl}_{2} . \mathrm{H}_{2} \mathrm{O}$ and $0.06 \mathrm{gL}^{-1}$ of yeast extract were placed in the beaker and stirred using magnetic stirer. The liquid medium were transfered to schott bottle and autoclaved for 15 minutes at $112^{\circ} \mathrm{C}$. Glucose and $\mathrm{MgSO}_{4} \cdot 7 \mathrm{H}_{2} \mathrm{O}$ were added into the medium after being 
autoclave.

\subsection{Inoculum Preparation}

Single colony of bacteria isolated was inoculated into Ramsay broth at $30^{\circ} \mathrm{C}$ for 24 hours in an orbital shaker at $200 \mathrm{rpm}$. A total of $10 \%$ of the cultured bacteria with OD 0.5 and above at $600 \mathrm{~nm}$ were used as inoculum. The dense cultures $\left(1 \times 10^{7}\right)$ were harvested for further use.

\subsection{Soil Preparation}

$10 \mathrm{~kg}$ soil was sieved through $0.20 \mathrm{~mm}$ sieve size. The physical analysis of soil $(\mathrm{pH}$, temperature \& moisture content) was determined according to the [1].1 liters of oil sludge $(10 \% \mathrm{v} / \mathrm{v})$ was sprinkled over the sieved soil and allowed to get adsorbed for 30 minutes for further bioremediation studies [19].

\subsection{Experiments Set-up}

The ability of bacteria isolate to remediate oil sludge contaminated soil was analyzed by carrying out the biodegradation experiment in bioreactor $(60 \mathrm{~cm} \times 40 \mathrm{~cm} \times 20 \mathrm{~cm})$. Five treatments $(\mathrm{A}, \mathrm{B}, \mathrm{C}, \mathrm{D}$, \& E) were prepared in duplicate at open and air ventilated with following treatment combination:

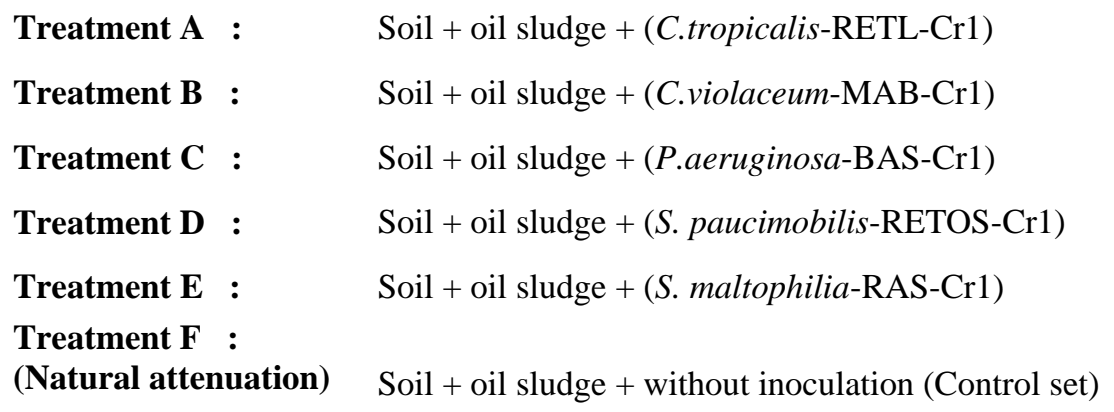

\subsection{Technical Procedures Protocol}

For each of the experimental unit the soils were tillage every day and watering with sterile distilled water at an interval 2 days to maintain the water holding capacity of soil. The bioreactors were supplied with 3 tubing for continuous aeration using air pump (Model RESUN LP100 Low Noise Air Pump). 10\% (v/v) of inoculants of each single culture were added into the plot containing $10 \mathrm{~kg}$ of soil contaminated with $10 \%$ of oil sludge. The inoculation of single culture into each plot was done for every 2 weeks during 60 days of treatment periods. Initial readings were taken immediately after the inoculation of the bacterial culture and further. The soil samples were drawn after every 7th day from the respective experimental unit and were analyzed up to 60 days incubation periods.

\subsection{Physiochemical Analysis of Soil}

\section{$2.8 .1 \mathrm{pH}$}

Analysis pH was carried out as according to [2]. $20 \mathrm{~g}$ of soil were weighed and mixed in a beaker contain 40 $\mathrm{ml}$ of distilled water. Analysis was done by taking three reading for accuracy using the $\mathrm{pH}$ meter.

\subsubsection{Soil Moisture Content}

The soil moisture were analysed by using gravimetric method as described by [6]. An empty crucible was weighed and record as (M1). Then, $10 \mathrm{~g}$ of soil sample were grained with mortar and pestle and recorded as (M2). The soil samples were dry at $110^{\circ} \mathrm{C}$ for 24 hours in an oven. Let the soil being cooled in desiccator and weighed the crucible as (M3). The soil moisture content was measured by using the formula below:

$\mathrm{M} 1=$ Weight of empty crucible $(\mathrm{g})$

$$
\% \text { Moisture content }=\frac{(M 2-M 3)}{(M 2-M 1)} \times 100
$$

M2 $=$ Wet of crucible + wet soil in $(\mathrm{g})$

M3 = Weight of crucible + dry soil in $(\mathrm{g})$ 


\subsubsection{Soil Microbial Population}

The growths of microorganism in each plot soil were determined according to method APHA 9215. Analyses were carried out weekly in each plot study. $10 \mathrm{~g}$ of soil sample was mixed with $100 \mathrm{ml}$ sterile distilled water by diluting $1 \mathrm{ml}$ of soil sample into $9 \mathrm{ml}$ of sterile distilled water (dilution plate technique). The dilution series from $10^{-3}$ until $10^{-5}$ were chosen to calculate the biological population. $0.1 \mathrm{ml}$ of culture was spreader into Nutrient agar and incubated at $300 \mathrm{C}$ for 24 hours. The total CFU were calculated based on the colony growth in the agar.

\subsection{Total Petroleum Hydrocarbon (TPH) Analysis}

Total petroleum hydrocarbon were carried out based on gravimetric method (Soxhlet extraction) (USEPA $354^{\circ} \mathrm{C}$ ) [20]. $20 \mathrm{~g}$ of soil sample was grained and placed in thimble and extracted with dichloromethane (DCM). Then the thimble was placed in soxhlet extractor. $175 \mathrm{ml}$ of dichloromethane was added into round bottomed flask (RBF). After that the soxhlet extraction were arranged and mixed with enough dichloromethane until it covers the thimble. The cooling temperature and mantel heater was set at $17^{\circ} \mathrm{C}$ and $4^{0} \mathrm{C}$ respectively. The extraction process takes places for less than 24 hours. Then the content was cooled and let the DCM flow to the round bottomed flask from the extractor. The total solvent was cleared completely with the vacuum evaporator at $40-50^{\circ} \mathrm{C}$. By using the rotary pump, let DCM left the sample. The RBF together with the extract was cooled in desiccator after being dried in oven at $40^{\circ} \mathrm{C}$. The RBF was measured until constant weighed obtained. The percentage of total petroleum hydrocarbon (TPH) was calculated using the formula below:

$$
\% T P H=\frac{\text { Min extract weight in } R B F}{\text { Weight of sample }} \times 100
$$

\section{Results \& Discussion}

\subsection{Oil sludge degradation}

The profile reduction of TPH in five different treatments plots at 5\% and $10 \%$ concentration of oil sludge are shown in Figure 3.1 (a-e). Two control sets (natural attenuation) which consisted of contaminated soil sample with indigenous microorganisms were also analyzed.

The efficiency of five different selective oil degrading bacteria in enhancing the oil sludge contaminated soil at different concentration levels are shown in Figure 3.1(a-e). The initial TPH of oil sludge at 5\% concentrations are $50 \mathrm{~g} / \mathrm{kg}$ while at $10 \%$ concentration was $100 \mathrm{~g} / \mathrm{kg}$ respctively. The results obtained showed that all five set treatments in both concentration studied were in the same pattern profiles with dramatic reduction of TPH within the first 14 days of incubation periods. The TPH value rate after 15 days treatments was significantly slow and continued to decrease until the end of 60 days treatment. Generally in all set treatments, each strains showed comparable performances in degrading oil sludge whereby they can achieved a removal of TPH more than $60 \%$ as compared to natural attenuation (control plot).
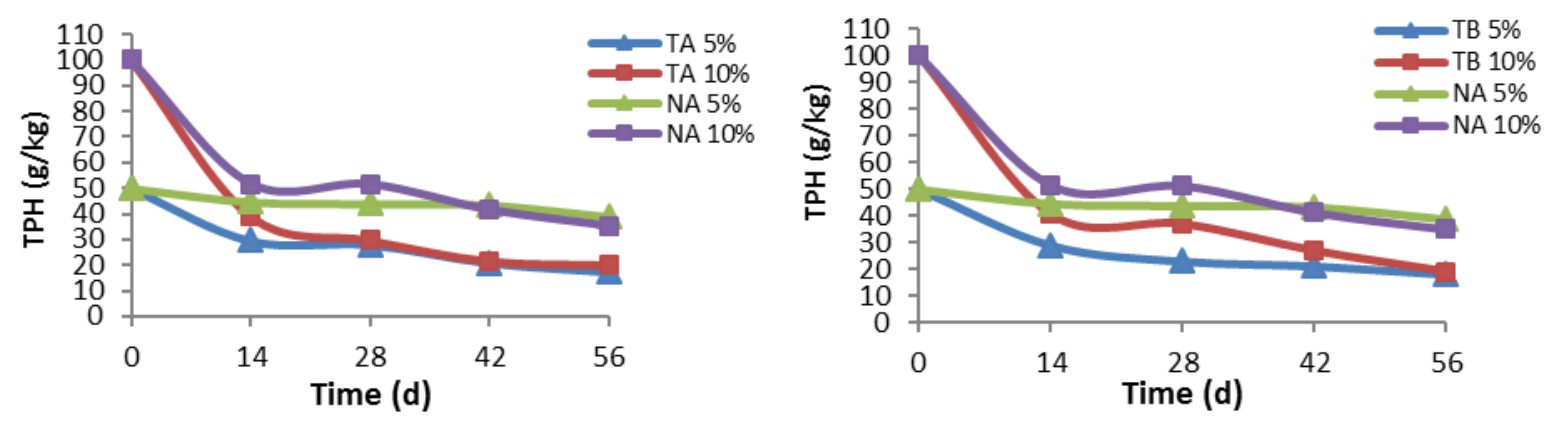

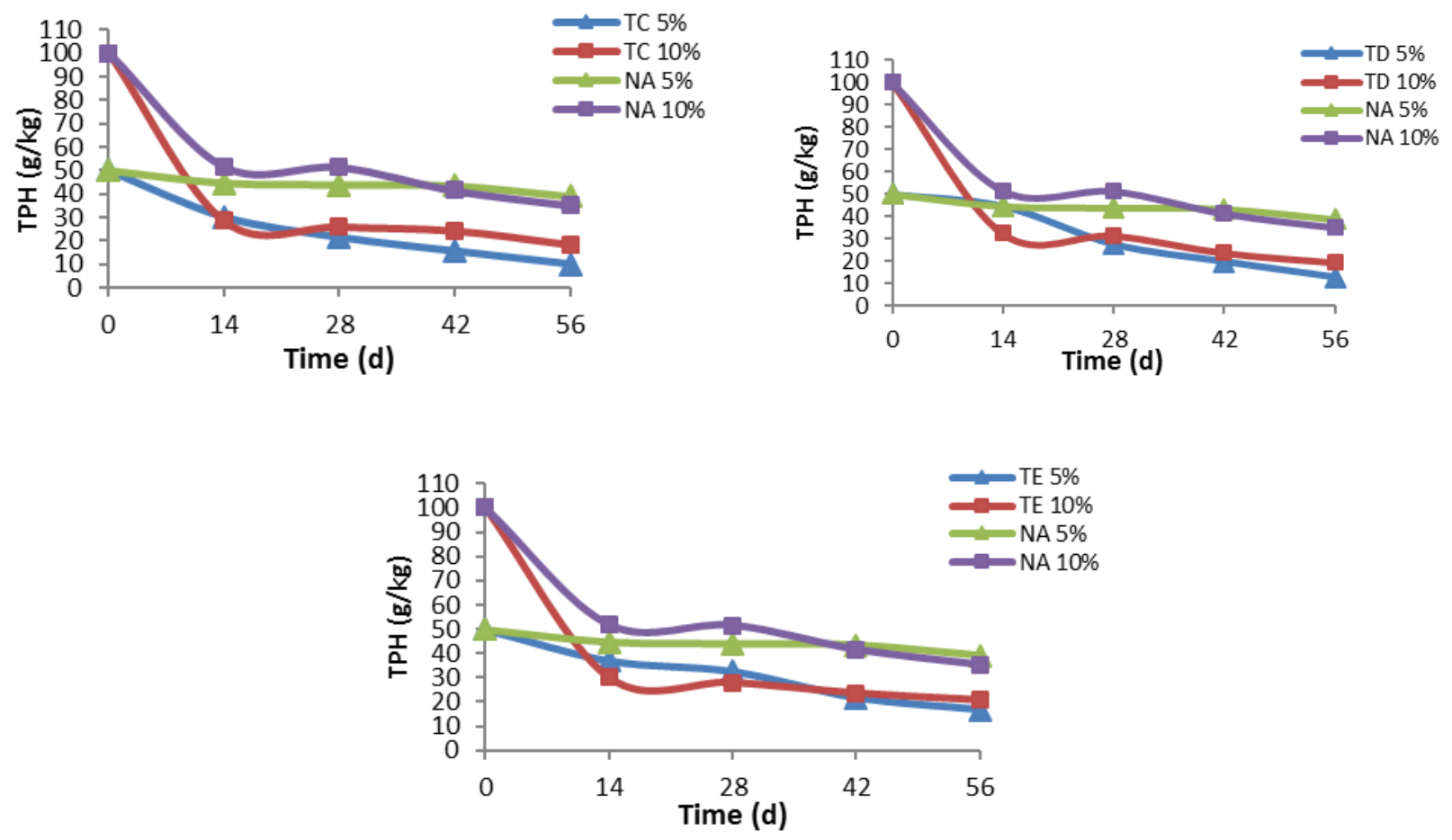

Fig 3.1: Profile of TPH reduction at different concentration levels of oil sludge contaminated soil during 60 days incubation periods. a: Treatment with C. tropicalis-RETL-Cr1 (TA); b: Treatment with C. violaceum-MAB-Cr1 (TB); c: Treatment with P. aeruginosa-BAS-Cr1(TC), d: Treatment with S. paucimobilis-RETOS-Cr1(TD), e: Treatment with S. maltophilia-RAS-Cr1 (TE)

It was observed that the rate of biodegradation of oil sludge at 5\% concentration were higher in treatment with P.aeruginosa-BAS-Cr1 $\quad(80 \%)>S$. paucimobilis-RETOS-Cr1 $\quad(74 \%)>S . \quad$ maltophilia-RAS-Cr1 $(67 \%)>$ C.tropicalis-RETL-Cr1 $(65 \%)>$ C.violaceum-MAB-Cr1 $(64 \%)$. For treatment at $10 \%$ concentration oil sludge, the ranking for hydrocarbon degradation performances are as followed P.aeruginosa-BAS-Cr1 $(81.6 \%)>$ C.violaceum-MAB-Cr1 $\quad(80.7 \%)>S . \quad$ paucimobilis-RETOS-Cr1 $\quad(80.4 \%)>C . t r o p i c a l i s-R E T L-C r 1$ $(80 \%)>$ S. maltophilia-RAS-Cr1 (79.2\%). In comparison, natural attenuation showed the lowest degradation at $5 \%$ and $10 \%$ concentration of oil sludge with only $22 \%$ and $54 \%$ after 60 days of incubation. This findings concluded that augmentation with single strain P.aeruginosa-BAS-Cr1 performed best in the bioremediation of oil sludge at 5\% and 10\% concentration showing a small amount residual of hydrocarbon contaminant with only $10 \mathrm{~g} / \mathrm{kg}$ and $18.4 \mathrm{~g} / \mathrm{kg}$ respectively. The results also demonstrated that the higher contaminants levels in soil, the higher removal TPH can be achieved by 3.5 fold than in natural attenuation plot.

This performance indicates that all the five strains used in this study were capable to survive and degrade concentrations of oil sludge tested. However, different strains inoculated showed a different oil degradation capacity at a different time study. Mishra [11], reported that bioaugmentation by using microbial inoculants has been a common practice, since it could enhance the rate of biodegradation. Our results were consistent with many previous studies indicating that bioaugmentation was more efficient than natural attenuation. Farid [5], reported that effect of bioremediation of crude oil contaminated dessert oil by bioaugmentation of Pseudomonas genera in bio pile systems had showed that initial crude oil $277.5 \mathrm{~g}$ have been reduced up to $77 \%$ (TPH) after 155 days treatment. These results showed the highest TPH reduction as compared to bioavailability treatment (55\%), biostimulation (23\%) and biocontrol over 4\%. Previous studied by Fagbemo, reported that the effectiveness of augmented consortia Bacillus coagulans, Citrobacterkoseri and Serratiaficaria in diesel polluted soil have been conducted in an open tray $(13.5 \mathrm{~cm} \times 8.5 \mathrm{~cm} \times 4 \mathrm{~cm})$ internal dimension. The initial oil concentration at day 0 was $246097.02 \mathrm{mg} / \mathrm{g}$ have been degraded to $64439.55 \mathrm{mg} / \mathrm{g}$ after 18 days treatment. They reported that $73.82 \%$ reduction of oil were effective in augmented treatments as compared to natural attenuation $(41 \%)$ and control plot $(35.8 \%)$. 


\subsection{Environmental Parameters Influencing Bioremediation of Oil Sludge}

The variation of environmental parameters monitored during 60 days treatment is shown in Figure 3.2-3.4. Environmental conditions influencing bioremediation such as microbial population, $\mathrm{pH}$ and soil moisture content were also discussed in this paper.

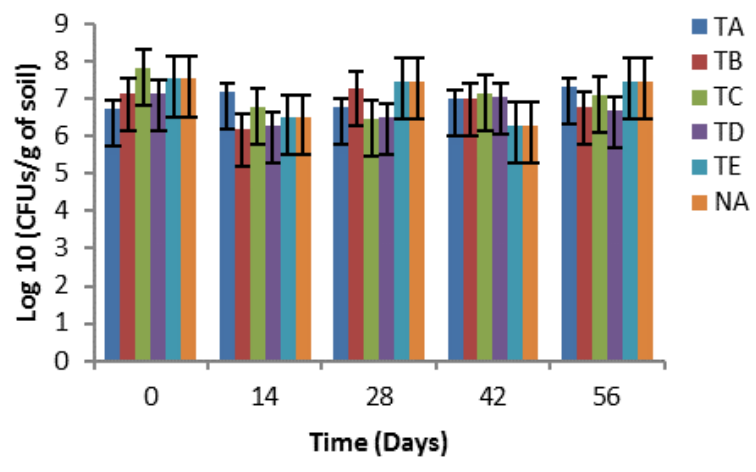

(a)

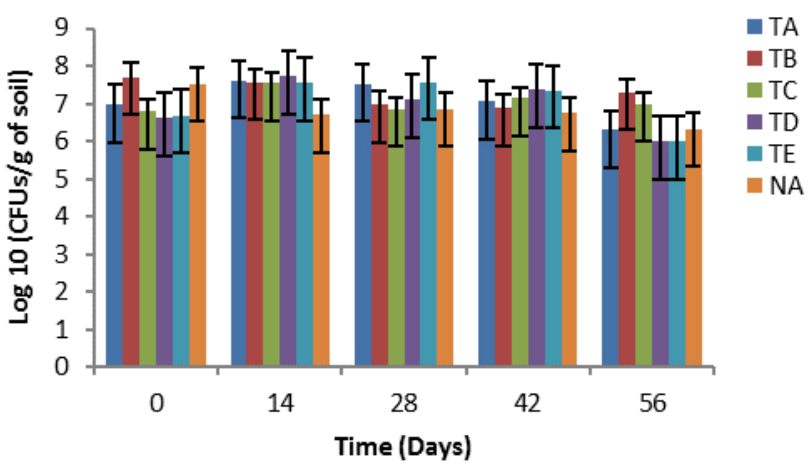

(b)

Fig 3.2: Viable cell counts with different treatments at (a) $5 \%$ and (b) $10 \%$ concentration of oil sludge within 60 days experiment studies

Fig 3.2 (a-b) showed the profile of viable cells counts at different treatments studied. Treatments with 5\% concentration of oil sludge had showed that all five strains C.tropicalis-RETL-Cr1, C. violaceum-MAB-Cr1, P. aeruginosa-BAS-Cr1, S. paucimobilis-RETOS-Cr1and S. maltophilia-RAS-Cr1 recorded a higher viable cell count at the initial of incubation periods with range $1.58 \times 106$ to $6.6 \times 107$. On the other hand, treatment at $10 \%$ concentration oil sludge the number of viable cell was observed in the range of $1.0 \times 106$ to $5.2 \times 107$ respectively. It was conclude that the number of viable cells at different treatments and concentrations studied was varied as a function of time. In contrary, the control plot (Natural Attenuation) for both concentrations studied recorded the lowest cells value during day 14, 28 and 42 treatment period. The results on viable cell counts showed that the single culture of bacteria strains inoculated in the treatment of soil can withstand the toxicity of $5 \%(\mathrm{v} / \mathrm{v})$ and $10 \%(\mathrm{v} / \mathrm{v})$ oil sludge added. These bacteria strains able to grow under extreme condition and show increase in CFU. According to Scragg [17], the soil microorganism number should be in the range of $1.0 \times 107 \mathrm{CFUs} / \mathrm{g}$ soil for successful biodegradation. It is also necessary that the microorganisms can develop catabolic activity in order to transform the target contaminant [10][13].

\subsection{Changes of pH During Bioaugmentation Treatments}
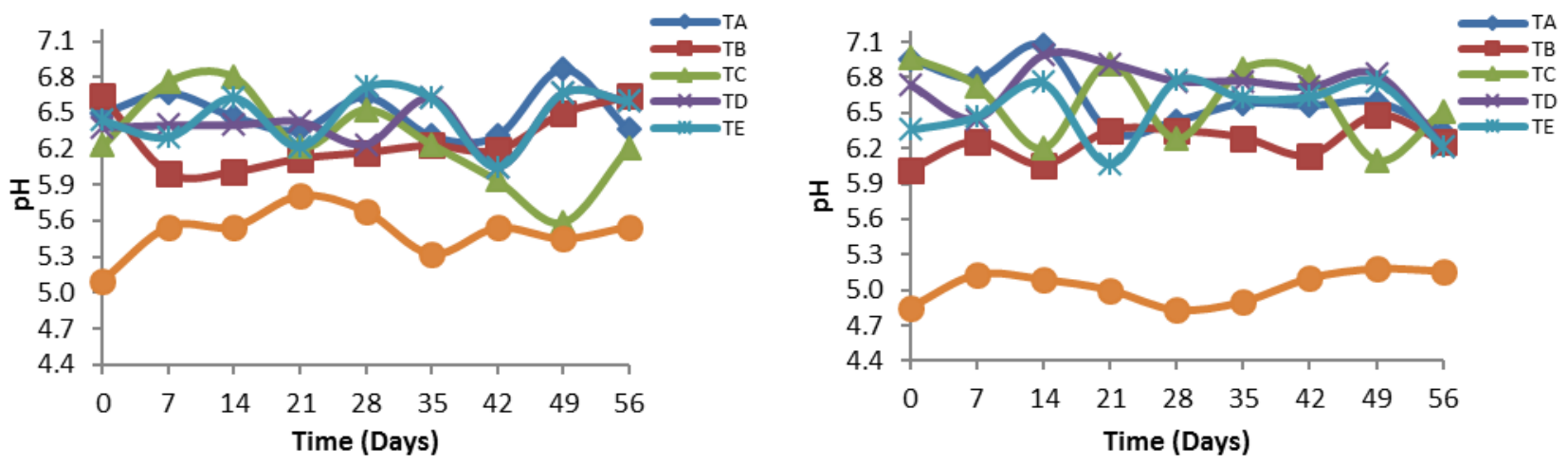

Fig 3.3 Variation of $\mathrm{pH}$ at five different treatments during 60 days incubation periods, (a) 5\% concentration of oil sludge, (b) $10 \%$ concentration of oil sludge

Fig 3.3 indicated the $\mathrm{pH}$ profile for five different treatments at $5 \%$ and $10 \%$ concentrations of oil sludge 
studied. Treatment with 5\% concentration of oil sludge had showed that the $\mathrm{pH}$ of the soil are range from 5.6 to 6.9 while at $10 \%$ concentration oil sludge, the $\mathrm{pH}$ values were 6.0- 7.0. Control plot (NA) at both concentrations studied recorded the acidic $\mathrm{pH}$ value with 4.8-5.1. The results also showed that during bioremediation process, the fluctuations of $\mathrm{pH}$ at all soil treatments were more pronounced but they did not go out of the range 4-8. The optimal $\mathrm{pH}$ for oil degrading in this study is in $\mathrm{pH}$ 6.4. This indicates that the optimum soil $\mathrm{pH}$ for hydrocarbon biodegradation also depends on the type of microbial species present. Some microorganisms can survive in a wide range of $\mathrm{pH}$, but others are sensitive to small variations. The effective range of soil $\mathrm{pH}$ recommended by Das \& Dash [3] is 5.5 to 8.5 and the USEPA [21] suggests the optimum range of $\mathrm{pH}$ for successful bioremediation from 6 to 8 .

\subsection{Soil Moisture Content during Bioremediation Process}

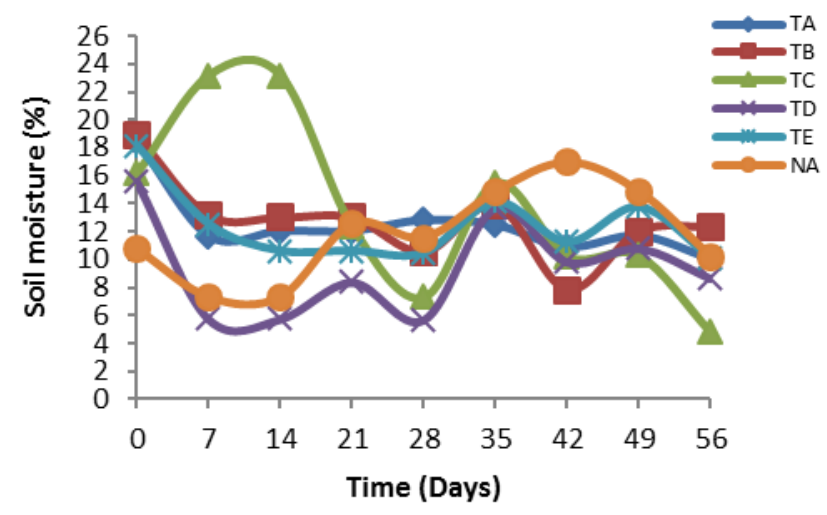

(a)

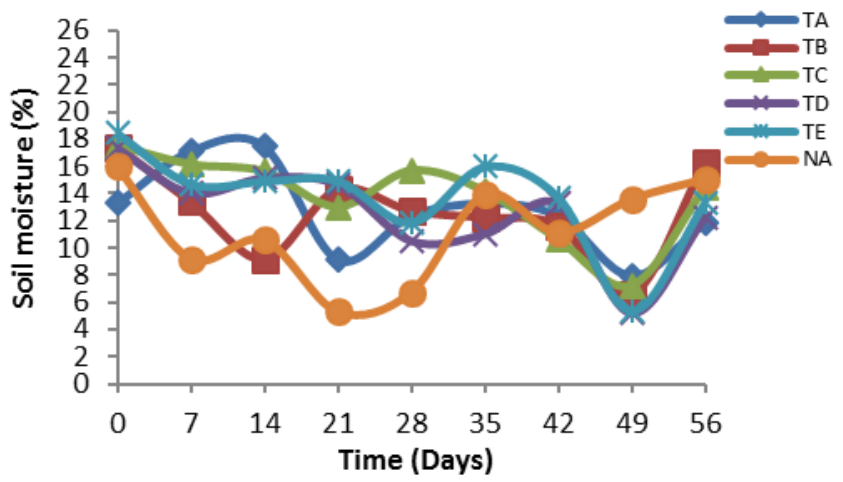

(b)

Fig 3.5: Variation of soil moisture content at five different treatments during 60 days incubation periods, (a) $5 \%$ concentration oil sludge, (b) $10 \%$ concentration oil sludge

The variations of soil moisture content studied are shown in Figure 3.5. The results showed that the range values for soil moisture in all treatments are $5-23 \%$. Treatment with $\mathrm{P}$. aeruginosa-BAS-Cr1 at 5\% concentration of oil sludge showed the high moisture content during week 1 and 2 with $23 \%$ respectively. At $10 \%$ concentration studied, soil bioaugmentation with C.tropicalis-RETL-Cr1 was observed the highest soil moisture with $17 \%$. The optimum value for soil moisture content in this study was observed in range $13 \%$. According to the Ronen [16], soil with below $10 \%$ moisture will inhibit the degradation process. This fact suggested that low soil water contents decreased activity of bacteria due to diffusion limitation of substrate supply and adverse physiological effects associated with cell dehydration. Thus this will primarily affect the rate of oil degradation in the soil and in turns, many microorganisms will die. Besides that, the loss of moisture content in the soil may due to several reasons such as evaporation due to hot weather, uptake of water for microbial activity and insufficient frequency of watering into the soil [18]. Our studied suggest that to soil moisture content can be enhanced by watering everyday to improve and maintain the moisture level.

\section{Conclusion}

This study concluded that treatment using P. aeruginosa-BAS-Cr1 was the best performance in degrading oil sludge at $5 \%$ and $10 \%$ concentration studied. It was observed that an increase of oil sludge in soil resulted in different removal efficiency of TPH for all five strains studied. Among the different strains, P. aeruginosa-BAS$\mathrm{Cr} 1$ can contributed as a potential strain that can be further exploited in other treatment process. However, we recommended more frequency of soil watering in order to achieve the optimum condition of soil moisture needed for microbial activity. 


\section{Acknowledgements}

This study was financially supported by a grant (GUG0035-SG-P-1/2016) from the Center of Research \& Innovation, Universiti Malaysia Sabah. We are indebted to Department of Environment (DOE) Malaysia and Labuan Shipyard \& Engineering Sdn. Bhd. for granting us permission to use and treat the oil sludge for this research.

\section{References}

[1] S. Chen, B. Mulgrew, and P. M. Grant, "A clustering technique for digital communications channel equalization using radial basis function networks," IEEE Trans. on Neural Networks, vol. 4, pp. 570-578, July 1993. (Use "References" Style) (Periodical style)

https://doi.org/10.1109/72.238312

[2] A. Cichocki and R. Unbehaven, Neural Networks for Optimization and Signal Processing, 1st ed. Chichester, U.K.: Wiley, 1993, ch. 2, pp. 45-47. (Book style)

[3] R. A. Scholtz, "The Spread Spectrum Concept," in Multiple Access, N. Abramson, Ed. Piscataway, NJ: IEEE Press, 1993, ch. 3, pp. 121-123. (Book style with paper title and editor)

[4] W. D. Doyle, "Magnetization reversal in films with biaxial anisotropy," in Proc. 1987 INTERMAG Conf., 1987, pp. 26. (Published Conference Proceedings style)

[5] G. W. Juette and L. E. Zeffanella, "Radio noise currents n short sections on bundle conductors," presented at the IEEE Summer Power Meeting, Dallas, TX, June 22-27, 1990. (Presented Conference Paper style)

[6] N. Kawasaki, "Parametric study of thermal and chemical nonequilibrium nozzle flow," M.S. thesis, Dept. Electron. Eng., Osaka Univ., Osaka, Japan, 1993. (Thesis or Dissertation style)

[7] J. P. Wilkinson, "Nonlinear resonant circuit devices," U.S. Patent 3624 12, July 16, 1990. (Patent style)

[8] Transmission Systems for Communications, $3^{\text {rd }}$ ed., Western Electric Co., Winston-Salem, NC, 1985, pp. 44-60. (Handbook style)

[9] R. J. Vidmar. (August 1992). On the use of atmospheric plasmas as electromagnetic reflectors. IEEE Trans. Plasma Sci. [Online]. 21(3). pp. 876-880. Available: http://www.halcyon.com/journals/21ps03-vimar (Journal Online Sources style) 